\title{
A FRAMEWORK FOR DESIGNING WORK SYSTEMS IN INDUSTRY 4.0
}

\author{
Kadir, Bzhwen A (1); Broberg, Ole (1); Souza da Conceição, Carolina (1); Jensen, Nik Grewy (2) \\ 1: Danish Technical University (DTU); 2: Dansk IngeniørService A/S
}

\begin{abstract}
The introduction of new digital technologies in industrial work systems and increasing implementation of Cyber Physical Systems are evoking new and unknown challenges and opportunities related to aspects of human work and organisation. To ensure human wellbeing and overall system productivity, there is a need for interdisciplinary methods and approaches for dealing with the challenges and taking advantage of the opportunities. In this paper, we present a conceptual framework for designing Industry 4.0 enabled work systems, which serves to accommodate this need. The framework combines elements and principles of Design- and Lean thinking methodologies and Human Factors and Ergonomics, thus making it a practical, systematic, and iterative, human centred approach. We use examples from a retrospective industrial case study to illustrate elements of the framework and provide several implications for practitioners.
\end{abstract}

Keywords: Industry 4.0, Lean design, Collaborative design, Organizational processes, Technology

\section{Contact:}

Kadir, Bzhwen A

Danish Technical University (DTU)

Management

Denmark

bkad@dtu.dk 


\section{INTRODUCTION}

The road towards Industry 4.0 leads to an unclear destination, with many uncertainties and unexpected challenges (Qin et al., 2016). While the benefits of new digital technologies are irrefutable, so are the related challenges emerging with the introduction of these novelties into industrial work systems. The term Industry 4.0 originated from Germany's initiative to increase industrial competitiveness through digital technologies (Kagermann et al., 2013) and is similar to the American equivalent, Smart Manufacturing (Davis et al., 2015). These terms refer to the dynamic growth of technological capabilities and the ever-evolving digitalisation initiative that has become a permanent bullet point on the agenda of many industrial companies.

One of the key concepts behind Industry 4.0 is Cyber-Physical Systems (CPS). CPS are complex sociotechnical systems where physical and virtual elements overlap and humans and technology co-exist and co-operate in solving complex tasks (Wang et al., 2015). Such digitally enhanced work systems are sparking changes and complexities in organisation structures, workplace arrangement, and the way people work and perform daily routines (Longo et al., 2017). In addition, the roles and responsibilities of human workers are changing with the increasing automation of work, removing certain job positions and tasks, while paving the way for new ones (Lorenz et al., 2015).

To realise the benefits of Industry 4.0, there is a need to address these emerging changes through the implementation of interdisciplinary approaches for qualifying strategies and suitable human-technology solutions that can create transparency for the human workers (Gorecky et al., 2014). There is a requirement of new human-centric design and engineering philosophies that focus on enhancing the human's sensorial, cognitive and physical capabilities (Romero et al., 2016). To accommodate this requirement, it will be necessary to explore, test and validate new approaches for designing Industry 4.0enabled work systems founded on the combination of different existing concepts and methods.

Our contribution in this paper is a framework that combines elements from Design- and Lean thinking methodologies with Human Factors and Ergonomics (HF/E) that serves to guide the process of designing Industry 4.0-enabled work systems. We believe that combining these three methods would be beneficial because 1) Design thinking provides a method for dealing with novel and innovative ideas, which could be useful in the case of introducing new and untested digital technologies in industrial work systems that might result in new ways of working and organising work. 2) HF/E ensures considerations regarding human well-being and human-technology interactions. 3) Lean thinking is a concept many industrial companies are familiar with and it provides a systematic approach for improving work systems. The addition of Lean makes a great vehicle for delivering such a new approach because it includes terminologies and methods most companies are already familiar with, which could potentially increase the usability of the framework. The framework is, on the one hand, a prescriptive tool that practitioners can use in the process of (re)designing Industry 4.0-enabled work systems. On the other hand, it can function as a diagnostic tool that academics can apply to analyse and understand the (re)design process of a work system.

The International Ergonomics Association defines HF/E as 'the scientific discipline concerned with the understanding of interactions among humans and other elements of a system, and the profession that applies theory, principles, data and methods to design in order to optimise human well-being and overall system performance' (IEA, 2018). Design thinking provides a user-centred approach to innovation that focuses on using sensibility and methods to identify needs, brainstorming and prototyping (Brown, 2009; Carlgren et al., 2014). In addition, as a response to the increasing digitalisation in recent years, the concept of design sprints has emerged as a new key method for designing digital products and services (Banfield et al., 2016; Knapp et al., 2016). Because the design of Industry 4.0-enabled work systems includes unfamiliar and untested elements and interactions, using design thinking could be beneficial in overcoming the related challenges.

Combining HF/E and design practices is not new and the concept of Human-Centred Design (HCD) is an example of this combination. HCD combines these two methods with the intent of designing and developing more usable interactive systems (BSI Group, 2010; Giacomin, 2014). While Design thinking and HF/E are not widely adopted approaches in industry, Lean thinking, also referred to as Lean production, is a well-known and common approach used by industrial companies to, for example, improve quality, eliminate waste, create flow, organise work and continuously improve work processes (Womack and Jones, 2003). In addition to Lean production, lean thinking has also branched into digital product development, that is, the Lean start-up concept (Ries, 2011), from which we also include 
elements in the suggested framework. Thus, our objective with this framework is to provide a practical, human-centred, systematic yet iterative approach for implementing new digital technologies in industrial work systems.

The organisation of the rest of this paper is as follows: In Section 2, we explain the methodology used to achieve the results of this paper. In Section 3, we present the results and the proposed framework for designing Industry 4.0-enabled work systems. In Section 4, we discuss the results and findings, implications for practitioners as well as highlighting the limitations of the paper and make suggestions for future research. Lastly, in Section 5, we summarise the paper and provide concluding remarks.

\section{METHODOLOGY}

We combined two different methodological approaches to achieve the results presented in this paper. We used existing theories and models to develop a conceptual framework for designing Industry 4.0-enabled work systems as well as conducting case studies to highlight a 'best practice' of how industrial companies are currently dealing with the (re)design of industrial work systems in conjunction with the implementation of new digital technologies. We used the results of the best practice case study to present examples that illustrated aspects of the proposed framework. In Sections 2.1 and 2.2, we describe the methodology behind the framework and case studies, respectively.

\subsection{Developing a conceptual framework}

Our approach for developing the proposed framework focused on using existing methods and theories from different domains dealing with concepts and challenges that bear a resemblance to the topic of this paper, which is the (re)design of industrial work systems to accommodate unfamiliar and untested digital technologies. This approach is similar to what Zahra and Newey (2009) refer to as 'Mode 2: Borrowing and Extending'. This Mode 2 approach is suitable when combining well-known theories to a new phenomenon in a new setting at the intersection of different disciplines. We found this approach highly appropriate because our intent was to combine three different theories, Design-, Lean thinking and HF/E to explore the design of Industry 4.0-enabled work systems.

For the practical process of developing the conceptual framework, we followed the eight-phase approach presented by Jabareen (2009). These eight phases are 1) mapping the selected data sources, 2) extensive reading and categorising of the selected data, 3 ) identifying and naming concepts, 4) deconstructing and categorising the concepts, 5) integrating concepts, 6) synthesis, resynthesis and making it all make sense, 7) validating the conceptual framework, 8) rethinking the conceptual framework.

\subsection{Industrial case study}

Conducting case studies is an efficient way to collect empirical data and document current standard practices in industrial companies, thus connecting qualitative evidence to deductive research (Eisenhardt and Graebner, 2007). Since October 2017, the authors of this paper have conducted seven different retrospective and explorative case studies, investigating how industrial companies in Denmark approach the (re)design of work systems as the result of the implementation of new digital technologies. These companies were different in size and operated in different industries. To highlight differences and similarities amongst these case studies and identify a best practice approach, we analysed and compared the cases following the case study research approach by Yin (2009).

For this paper, we chose to focus on and use the results of one of these seven case studies, which we used to illustrate elements of the framework. The reason behind choosing this specific case study was the case company, which we will refer to as Company A, had what we considered a best practice approach for designing Industry 4.0-enabled work systems. We evaluated Company A's approach as best practice because they had a systematic approach, which included some design considerations in comparison to the other companies. The other companies had paid limited attention to design aspects when (re)designing their work systems and had plunged into implementation straightaway.

\subsubsection{Data collection}

The case study at company A consisted of qualitative data, which we collected through semi-structured interviews with two production development engineers, whom we will refer to as Respondent $\mathrm{A}$ and Respondent $\mathrm{B}$, who had been in charge of the redesign process and managing the pilot project. We carried out the interviews in face-to-face settings, audio-recorded and transcribed them in Danish. The 
interview with Respondent A had a duration of approx. 80 minutes while the interview with Respondent B lasted approx. 150 minutes. We were also able to observe the work system in operation using a participant observation type (Krause and Denzin, 1989) and took notes in accordance with Spradley (1980). Furthermore, the company granted us access to different materials such as PowerPoint presentations and photos the engineers had taken to document the process of the pilot project. We analysed the qualitative data with a focus on defining and describing the approach that Company A had applied to redesign their work system. In addition, we analysed and compared this approach to our proposed framework as well as identified examples from the case study, which we could use to illustrate elements of the framework.

\subsubsection{Case setting}

Company A is a large (>250) manufacturer of electric motors, generators and transformers. They have been on the path of Industry 4.0 for several years, implementing and incorporating digital solutions in their operational level work systems. Their strategic vision for the next five years also has an intense focus on the utilisation of new digital technologies. Company A has many work cells dedicated to the assembly of products with numerous single parts that are too expensive and complicated to automate. This challenge had forced the strategic level decision-makers (executive and senior management) to prioritise digitalisation over automation.

With digitalisation in mind, the decision-makers had identified certain technologies for implementation as well as choosing a specific work cell for a pilot project. This pilot project focused on digitalising a work cell by converting all essential information received on paper into a digital format in the form of a touch screen and linking product components and bill of materials through a handheld scanner, thereby going from being highly dependent on the use of paper to becoming completely paperless. In addition, this project relies on seamless information flow between the work system and adjacent departments, that is, planning and quality control, thus the project includes system integration, which Rüßmann et al. (2015) refer to as one of the pillars of Industry 4.0.

The decision-makers had assigned a small team consisting of production development engineers, software developers and the workers attached to the chosen work cell. With the team established, the pilot project had started with a small workshop where the participants had identified the essential elements they could start digitalising and had created and implemented a working version of the solution after a couple of weeks. Through interactive workshops and continuous feedback and suggestions from the workers, the team had used the initial version as a foundation for the final solution as they had added and tested new features and improved functionalities through iterations.

By a certain date, the team needed to have a viable standardised solution with the potential for a companywide rollout, thus constraining the time the team could spend on developing the solution further. At the time we conducted the case study, the pilot project was ending, and the work cell had experienced a noticeable increase in productivity as well as receiving positive feedback from the workers participating in the pilot project. The project team was still awaiting final formal evaluation from the decision-makers before the solution could roll out to other work cells in the company. Refer to Figure 1 for an overview of the company's process of the pilot project.

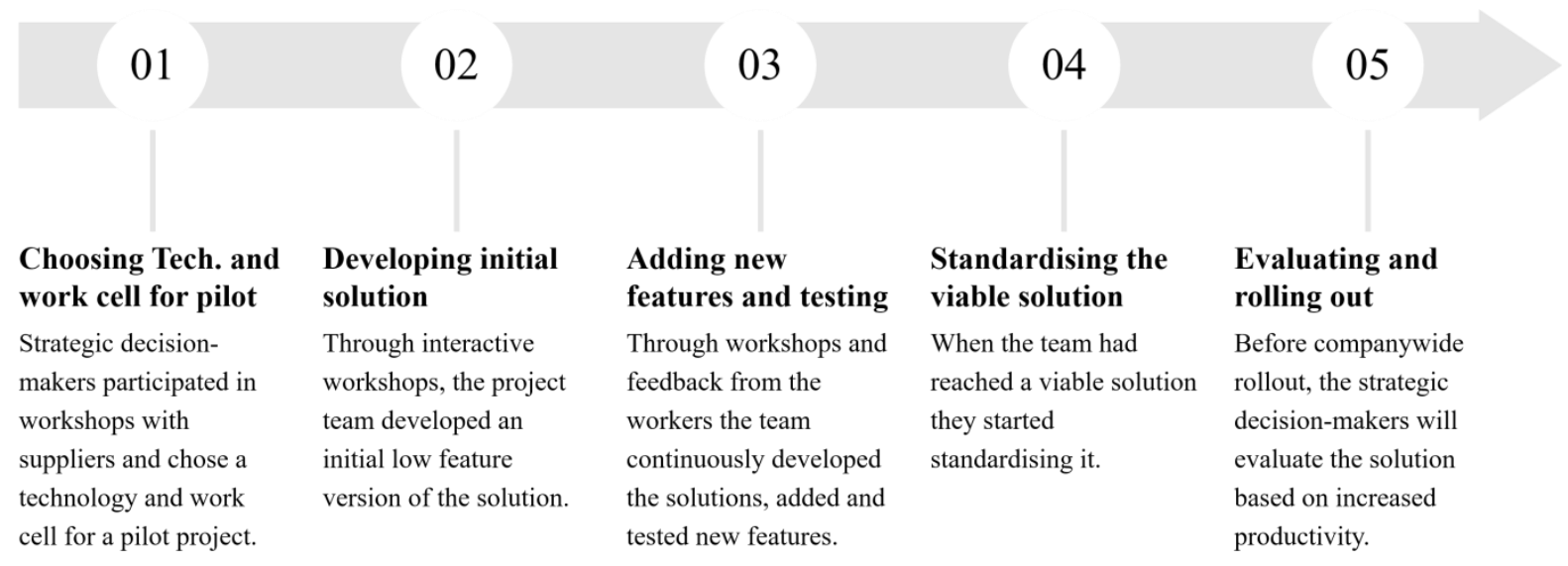

Figure 1. Overview of Company A's process for the work cell digitalisation pilot project. 


\section{RESULTS}

In this section, we present and explain the proposed framework for designing Industry 4.0-enabled work systems, and further explain and illustrate elements of the framework with examples from the case study described in Section 2.2.

\subsection{Conceptual framework}

The framework combines elements from Design- and Lean thinking, with HF/E and has three hierarchy levels, macro, meso and micro levels. The application of the framework is in the following four main phases: Understand, Define, Develop and Deliver. However, the (re)design of a work system is usually sparked and guided by strategic and tactical decisions made by a company's strategic level decisionmakers. In the framework, we refer to this initial phase as the Decide/Decision phase, which comes prior to the four main phases. In the Decide phase, strategic decisions refer to a company's vision and overall strategy, such as Company A's five-year digitalisation strategy. Tactical decisions serve the purpose of translating the company's strategy into tangible action items. In Company A's example, this is where they decided upon the specific technology, chose a work cell for a pilot project, allocated the necessary resources and assigned a team to the project. Figure 2 is an illustration of the framework in its entirety.

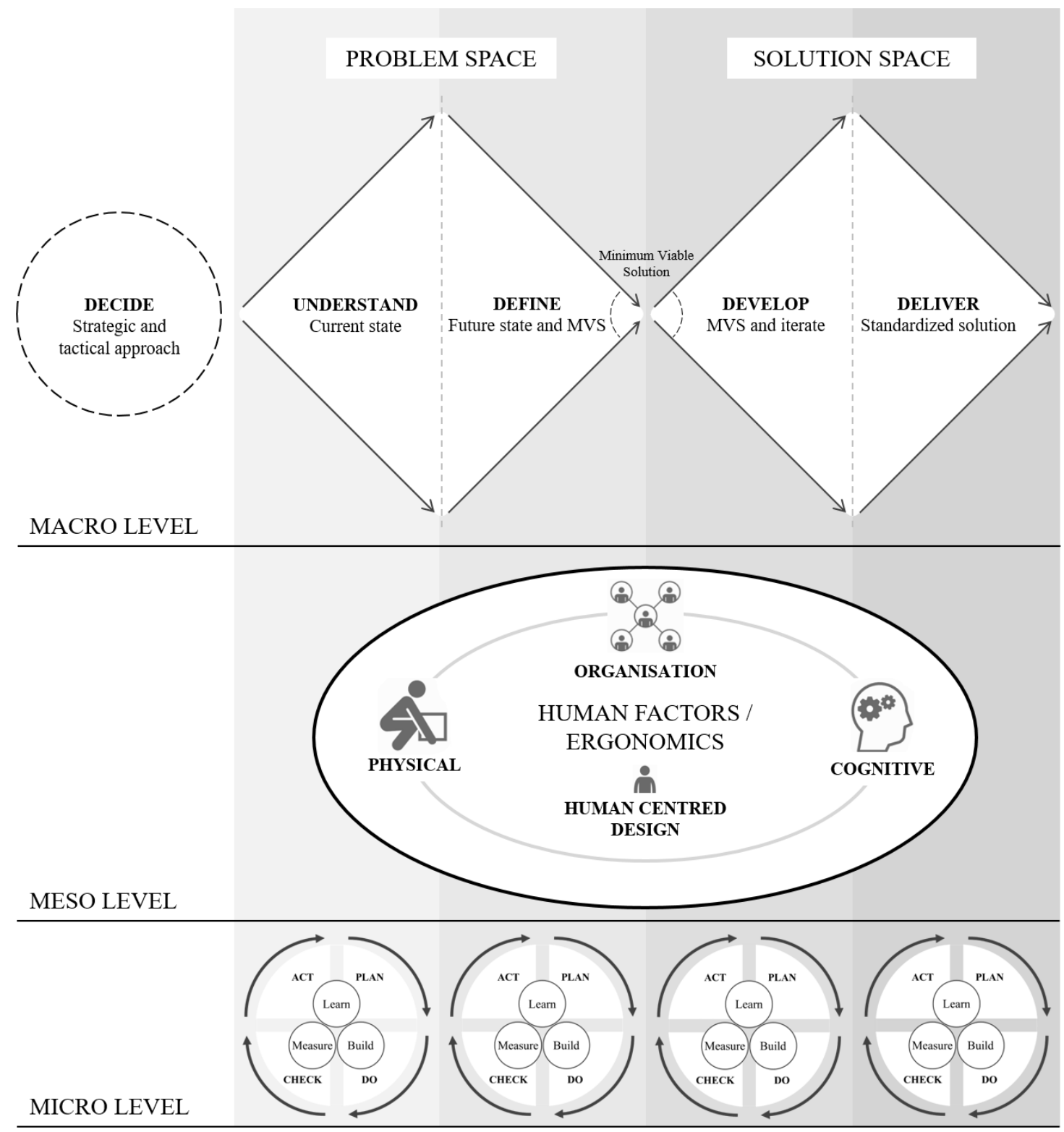

Figure 2. The proposed framework for (re)designing Industry 4.0-enabled work system. 


\subsubsection{Macro level}

The macro level is an overall approach for designing Industry 4.0-enabled work systems, which is similar to the double diamond approach (Design Council, 2007), in that it has a problem- and a solution space, each with one diverge and one converge phase. The 'Understand' and 'Define' phases are in the Problem space, while 'Develop' and 'Deliver' are in the solution space.

The purpose of the Understand phase is to get a holistic understanding of the current state of the work system and to identify wasteful activities as well as challenges related to productivity and HF/E. The purpose of the Define phase is to define what an improved future state of the work system with the novel digital technology might look like. This approach of establishing an understanding of the current state and current challenges, and defining an improved future state is typical of the process of Value Stream Mapping, which is closely linked to the main Lean principles and methodology (Abdulmalek and Rajgopal, 2007). The outcome of the Define phase is the identification of certain focus areas and the definition of criteria for a Minimum Viable Solution (MVS).

We define MVS as the smallest solution that provides the most amount of value and possibility to learn. The MVS is similar to - and inspired by - what Ries (2011) refers to as a Minimum Viable Product, which is a minimalistic version of a product that allows the fastest way to learn with the minimum amount of effort in the least amount of time. Thus, the MVS is the first version of a solution that has minimum specifications, is easy to design and develop, and easy to test, evaluate and improve upon. The aim of the MVS is to maximise value and shorten overall project duration while using minimum resources. In the case study, the team had started with an interactive workshop where they had defined criteria for an initial simple version of the solution, which did not include any of the advanced capabilities the chosen technology offered.

The beginning of the Develop phase focuses on developing an MVS based on the criteria established by the end of the Define phase. The objective of the rest of this phase is continuously to develop, test, learn and improve the MVS until reaching a viable final version of the solution. In the last phase, Deliver, the objective is to start standardising the final viable solution, which was the outcome of the Develop phase and getting the final pieces together before delivery to operations. In the Develop phase in the case study, after the team had established and created the MVS they focused on selecting and adding new features through a constant stream of iterations and making incremental continuous improvements to the initial solution, namely, their MVS. Closing in on the pilot project's deadline, the team had developed what they considered as a viable solution and moved into the Deliver phase. In the Deliver phase, they focused on creating Job Instructions, standardising the work surrounding the solution, and preparing for final evaluation and potential companywide rollout.

\subsubsection{Meso level}

The meso level focuses on operationalising the macro level design processes using HF/E methods and principles. Achieving the macro level objectives requires the inclusion of the different stakeholders, particularly the workers who are working in the current or will be working in the finalised work system. The workers need to be involved in creating an understanding of the current situation, defining the future state, providing continuous feedback as the MVS develops, and take part in the standardisation and delivery of the final solution. Stakeholder inclusion is achievable with the adoption of an HCD approach as in BSI Group (2010), thus, making HCD an important element of the framework's operationalisation. To account for HF/E and essential elements of the work system while working through the problem space and solution space at the macro level, we suggest using the three main domains of HF/E as defined by IEA (2018) and BSI Group (2016) as guiding principles. These three domains are physical, cognitive and organisational HF/E. In addition, incorporating a model such as the SOFT model (Horgen et al., 1999), could initiate thoughts and assist in identifying interdependent challenges and opportunities in the four dimensions of the workplace, which are spatial, organisational, financial and technological.

Drawing an example from the case study, the project managers had not deliberately made any specific considerations regarding the three main domains of HF/E, however, they had followed an approach similar to BSI Group (2010). Throughout the four phases, the project managers had made a great effort in gathering the different stakeholders through interactive workshops to discuss design decisions, learnings, iterations, improvements as well as planning upcoming tasks and following up on completed ones. In addition, the workers had been in charge of designing the new work processes and contributed with ideas and improvements for the design of the touchscreen's interface. The interviewees attributed the success of their solution in great part to this close collaboration between the stakeholders, and 
involvement of the shop floor workers. Although, we note that neither Respondent A nor Respondent B referred to this approach using the term 'HCD'. However, both respondents emphasised the importance that including the different stakeholders and granting the workers a feeling of ownership has on the success of a project.

\subsubsection{Micro level}

On the micro level, the focus is on managing the tasks related to achieving the macro level objectives of each phase and enabling the full benefits of the MVS requires a continuous loop of build, measure and learn (Ries, 2011). To ensure this continuous learning and adaptation, the suggested approach for managing tasks on the operational level is to follow the systematic approach of the Deming wheel, which divides tasks into the four phases of Plan, Do, Check, Act (PDCA) (Deming and William, 1986). This approach is an essential part of Lean thinking and is commonly used in industry for problem-solving, continuous improvements and quality management (Andersen, 2007). The Plan phase focuses on analysing and planning activities related to the tasks. In the Do phase, the focus is on carrying out the planned activities. In the Check phase, the aim is to measure and evaluate the effects of the activities. In the Act phase, the objective is to modify and follow up on the evaluations from the check phase. A positive evaluation means an acceptable result that might need standardisation, while a negative evaluation will typically result in a new PDCA cycle.

In the case study, the team had used a combination of the PDCA approach and the agile project management method, Scrum, as in Schwaber (2004), to manage the tasks related to the redesign of the work system. Respondent B mentioned that using this approach created a cycle of continuous learning and measurable improvements. To accommodate this approach, they had used a mix of soft and hard solutions, namely, a Microsoft Excel file and a whiteboard next to the work cell to highlight planned, in progress and completed activities. In a similar fashion, they had created a system for keeping track of errors, which the workers had actively used to report errors and shortcomings of the solution that needed attention and action.

\section{DISCUSSION}

The currently available literature dealing with the design of work systems in Industry 4.0 is limited. This limitation is especially true in regard to the design of work systems with considerations of HF/E. While publications such as Fellmann et al. (2017), Peruzzini and Pellicciari (2017), Pinzone et al. (2018), Stern and Becker (2017), Zezulka et al. (2016) have developed frameworks dealing with different specific topics related to human work in Industry 4.0, there is still a need for holistic and practical frameworks, which practitioners can follow when introducing new digital technologies.

Romero et al. (2016) emphasise the need for new prescriptive human-centred approaches for implementing CPS and Richter et al. (2018) highlight the need for diagnostic tools to study digital environments. Our contribution in this paper is a framework that serves both of these functions. It is a prescriptive tool, which practitioners can use to (re)design industrial work systems in conjunction with the introduction of novel and untested elements, such as new digital technologies, as well as a diagnostic tool, which academics can use to analyse existing work systems. Our framework is different from other frameworks in that it provides a pragmatic, human- and innovation-centred approach developed on the combination of well-established methodologies such as Design- and Lean thinking, and HF/E. To our knowledge, there is no other similar framework that combines these three methodologies with the purpose of designing Industry 4.0-enabled work systems.

In the industrial case studies we conducted, the case companies had paid limited attention to the design aspects of their work systems when introducing new digital technologies, ultimately skipping the design phase and getting into implementation straightaway. This was also the case for Company A, which we had evaluated as best practice. Neglecting design aspects and holistic work system understanding might result in the unsuccessful implementation of new technologies, for example, collaborative robots (Kadir et al., 2018). On the macro level of the proposed framework, the Understand phase in the Problem space aims at minimising this gap by gaining this holistic understanding and highlighting potential challenges while preparing for the related changes emerging with the implementation of any new digital technology. In addition, achieving such an understanding will align expectations and assist in defining a realistic and achievable future state as well as criteria for an MVS. We attribute Company A's ability to succeed with 
a limited design phase to the low complexity of the work system. Thus, the success rate of the project might have varied if the case had applied the same approach to a more complex work system.

The continuous development of digital technologies and increasing competition is leading to new ways of developing, testing and launching new products and services. As a response to this increasing demand, the concept of design sprints has emerged as a new key method for digital design (Banfield et al., 2016; Knapp et al., 2016). These new methods and traditional Design thinking methods such as Stanford (2018), which designers typically use for developing new products and services, are highly compatible with the concept of prototyping. However, in fast-paced industrial environments such as Company A, where work systems produce revenue-generating outputs, the concept of prototyping entire solutions is a luxury few companies can afford, thus, making the MVS a next best alternative to prototyping. The MVS allows for a quick start with a minimum amount of resources and grants the ability to build, measure and learn at a fast rate. The MVS also has the potential of limiting the related negative effects on the work system's performance indicators, for example, downtime, speed, quality and cost.

The addition of Lean thinking provides a systematic yet iterative approach for meeting the framework's macro level objectives. Because Lean thinking is common and widely known in industrial companies, it adds an element of familiarity to the framework, which might make it more comprehensible and increase the likelihood of its application. However, it is important to note that not all companies are familiar with Lean thinking and the PDCA approach (Lodgaard and Aasland, 2011). Nevertheless, the elements of Lean thinking presented in the framework such as the PDCA and the ideas of understanding the current state and its challenges as well as defining an improved future state and setting criteria for an MVS are not complex concepts and not too difficult to comprehend. In addition, the application of lean thinking and methods to deal with Industry 4.0 challenges is a highly discussed topic in industry as well as in academic publications. This combination is often referred to as Lean 4.0 (Mayr et al., 2018).

Incorporating $\mathrm{HF} / \mathrm{E}$ in the design of Industry 4.0-enabled work systems could be highly beneficial in accommodating workers' well-being. This is the reason we have HF/E as one of the three main elements of the proposed framework. With the integration of new digital technologies in industrial work systems, usability, user interfaces and human-machine interactions will need to become an essential element of consideration in regard to job design (Stern and Becker, 2017), and an HCD approach for the (re)design of work systems will be highly beneficial (Pacaux-Lemoine et al., 2017). We suggest that by following an HCD and keeping the three domains of HF/E in mind while working through the phases of the framework, it will be possible to accommodate the workers' needs sufficiently. In addition, it might also increase the workers' well-being throughout the design and implementation phases as well as operations.

\subsection{Implications for practitioners}

Our findings and the proposed framework are a shift in paradigm in regard to how practitioners are typically approaching the (re)design of industrial work systems. Instead of the common approach of jumping straight into implementation, a practitioner might consider spending some time on an initial design phase and focus on developing a viable solution to reduce the waste of time and resources. This framework is aimed at practitioners on a tactical and/or operational organisational level, who are in charge of introducing and incorporating new digital technologies and solutions into new or existing industrial work systems.

The industrial case study we used in this paper was at a large company that had the required resources for a pilot project as well as assigning a designated team to the project. Because of the number of resources required, this approach might not be fitting or realistic for most small- and medium-sized enterprises (SMEs). However, this does not mean that the framework is only applicable to large companies. On the contrary, we believe that this framework will be as beneficial to apply in SMEs as in large companies. Having a clear understanding of the current state and current challenges, and defining a clear vision for the future of the work system will align expectations and create a holistic understanding, which might be necessary to succeed with new digital technologies and new ways of working. In addition, a well thought out MVS might reduce the initial costs and resources needed to get started, which can be a barrier of entry for many SMEs. Following an approach such as the proposed framework, which divides digitalisation initiatives and projects into minor sprints and iterations might reduce this barrier of entry and offset project uncertainties. 


\subsection{Limitations and future research}

The limitation of this paper is that the proposed framework is only conceptual and that it has not been applied and tested in an industrial setting. Future research should address this limitation with prospective industrial case studies designed to test and evaluate the effectiveness of the framework, leading to further development and improvement of the framework. Furthermore, future research should also focus on providing specific methods and tools to apply in the different phases of the framework and provide more clarification and detailed descriptions on what to do, and how to do it.

\section{CONCLUSION}

Design is a crucial phase of the implementation of new digital technologies and companies should not neglect and skip this phase by jumping into implementation straightaway. In this paper, we presented a conceptual framework for designing Industry 4.0-enabled work systems and used an industrial case study to illustrate with examples some elements of the framework. The framework has two functionalities, in that it is a prescriptive tool for (re)designing work systems with novel elements such as new digital technologies, and it is a diagnostic tool for analysing existing work systems. Combined from the three methodologies of Design-, Lean thinking and Human Factors and Ergonomics, the framework provides a familiar, systematic, iterative, innovation- and human-centred approach for designing Industry 4.0-enabled work systems.

\section{REFERENCES}

Abdulmalek, F.A. and Rajgopal, J. (2007), "Analyzing the benefits of lean manufacturing and value stream mapping via simulation: A process sector case study", International Journal of Production Economics, Vol. 107 No. 1, pp. 223-236.

Andersen, B. (2007), Business Process Improvement Toolbox, 2nd edition, ASQ Quality Press, Milwaukee, Wisconsin.

Banfield, R., Lombardo, C.T. and Wax, T. (2016), Design Sprint, available at: https://www.innovationleader.com/downloads/DesignSprint.pdf (accessed 5 November 2018).

Brown, T. (2009), "Change by Design: How Design Thinking Transforms Organizations and Inspires Innovation", Harper Business.

BSI Group. (2010), "Ergonomics of human-system interaction: Human-centred design for interactive systems : ISO 9241-210", BSI Standards Publication, Vol. 2010 No. 4, p. 32.

BSI Group. (2016), "Ergonomics principles in the design of work systems (ISO / TS 6385:2016)”, BSI Standards Publication.

Carlgren, L., Elmquist, M. and Rauth, I. (2014), "Design thinking: Exploring values and effects from an innovation capability perspective", Design Journal, Vol. 17 No. 3, pp. 403-424.

Davis, J., Edgar, T., Graybill, R., Korambath, P., Schott, B., Swink, D., Wang, J., et al. (2015), "Smart Manufacturing", Annual Review of Chemical and Biomolecular Engineering, Annual Reviews, Vol. 6 No. 1, pp. 141-160.

Deming, W.E. and William E. (1986), Out of the Crisis : Quality, Productivity and Competitive Position, Cambridge University Press.

Design Council. (2007), Eleven Lessons: Managing Design in Eleven Global Brands: A Study of the Design Process, available at: www.designcouncil.org.uk (accessed 16 November 2018).

Doorley, S., Holcomb, S., Klebahn, P., Segovia, K. and Utley, J. (2018), Design Thinking Bootleg, available at: https://dschool.stanford.edu/resources/design-thinking-bootleg.

Eisenhardt, K.M. and Graebner, M.E. (2007), "Theory building from cases: Opportunities and challenges", Academy of Management Journal, Vol. 50 No. 1, pp. 25-32.

Fellmann, M., Robert, S., Büttner, S., Mucha, H. and Röcker, C. (2017), "Towards a Framework for Assistance Systems to Support Work Processes in Smart Factories", pp. 59-68.

Giacomin, J. (2014), "What Is Human Centred Design?”, The Design Journal, Joseph Giacomin, Vol. 17 No. 4, pp. 606-623.

Gorecky, D., Schmitt, M., Loskyll, M. and Zühlke, D. (2014), "Human-machine-interaction in the industry 4.0 era", Proceedings - 2014 12th IEEE International Conference on Industrial Informatics, INDIN 2014, pp. 289-294.

Horgen, T.H., Joroff, M.L., Porter, W.L. and Schon, D.A. (1999), "Excellence by Design: Transforming Workplace and Work Practice", Excellence by Design: Transforming Workplace and Work Practice, available at: https://doi.org/amazon.

IEA. (2018), "Definition and Domains of ergonomics", Açao Ergonômica, available at: https://www.iea.cc/whats/index.html (accessed 17 September 2018). 
Jabareen, Y. (2009), "Building a Conceptual Framework: Philosophy, Definitions, and Procedure”, International Journal of Qualitative Methods, Vol. 8 No. 4, pp. 49-62.

Kadir, B.A., Broberg, O. and Conceicao, C. (2018), "Designing human-robot collaborations in Industry 4.0: Explorative case studies", International Design Conference, pp. 601-610.

Kagermann, H., Wahlster, W. and Johannes, H. (2013), "Recommendations for implementing the strategic initiative INDUSTRIE 4.0", Final Report of the Industrie 4.0 WG, No. April, p. 82.

Knapp, J., Kowitz, B. and Zeratsky, J. (2016), "Sprint: How to Solve Big Problems and Test New Ideas in Just Five Days", Evolution.

Krause, D. and Denzin, N.K. (1989), "The Research Act: A Theoretical Introduction to Sociological Methods", Teaching Sociology, Vol. 17 No. 4, p. 500.

Lodgaard, E. and Aasland, K.E. (2011), “An examination of the application of Plan-Do-Check-Act cycle in product development”, ICED 11 - 18th International Conference on Engineering Design - Impacting Society Through Engineering Design, Vol. 10 No. PART 2, pp. 47-55.

Longo, F., Nicoletti, E. and Padovano, A. (2017), "Smart operators in industry 4.0: A human-centered approach to enhance operators' capabilities and competencies within the new smart factory context", Computers \& Industrial Engineering, Vol. 113, pp. 144-159.

Lorenz, M., Rüßmann, M., Strack, R., Lueth, K.L. and Bolle, M. (2015), "Man and Machine in Industry 4.0”, Boston Consulting Group, p. 18.

Mayr, A., Weigelt, M., Kühl, A., Grimm, S., Erll, A., Potzel, M. and Franke, J. (2018), "Lean 4.0-A conceptual conjunction of lean management and Industry 4.0", Procedia CIRP, Vol. 72, pp. 622-628.

Pacaux-Lemoine, M.-P., Trentesaux, D., Zambrano Rey, G. and Millot, P. (2017), "Designing intelligent manufacturing systems through Human-Machine Cooperation principles: A human-centered approach", Computers \& Industrial Engineering, Elsevier Ltd, Vol. 111, pp. 581-595.

Peruzzini, M. and Pellicciari, M. (2017), "A framework to design a human-centred adaptive manufacturing system for aging workers”, Advanced Engineering Informatics, Elsevier Ltd, Vol. 33, pp. 330-349.

Pinzone, M., Albè, F., Orlandelli, D., Barletta, I., Berlin, C., Johansson, B. and Taisch, M. (2018), “A framework for operative and social sustainability functionalities in Human-Centric Cyber-Physical Production Systems", Computers \& Industrial Engineering, Pergamon, available at: https://doi.org/10.1016/j.cie.2018.03.028.

Qin, J., Liu, Y. and Grosvenor, R. (2016), “A Categorical Framework of Manufacturing for Industry 4.0 and Beyond”, Procedia CIRP, Vol. 52, pp. 173-178.

Richter, A., Heinrich, P., Stocker, A. and Schwabe, G. (2018), "Digital Work Design”, Business \& Information Systems Engineering, Springer Fachmedien Wiesbaden, Vol. 60 No. 3, pp. 259-264.

Ries, E. (2011), The Lean Startup, 1st edition, Crown Publishing Group, New York, New York, USA.

Romero, D., Stahre, J., Wuest, T., Noran, O., Bernus, P., Fast-Berglund, Å. and Gorecky, D. (2016), “Towards an Operator 4 . 0 Typology: A Human- Centric Perspective on the Fourth Industrial Revolution Technologies", CIE 2016: 46th International Conferences on Computers and Industrial Engineering, pp. $0-11$.

Rüßmann, M., Lorenz, M., Gerbert, P., Waldner, M., Justus, J., Engel, P. and Harnisch, M. (2015), “Industry 4.0: The Future of Productivity and Growth in Manufacturing", available at: https://www.zvw.de/media.media.72e472fb-1698-4a15-8858-344351c8902f.original.pdf (accessed 10 May 2018).

Schwaber, K. (2004), Agile Project Management with Scrum, 1st edition, Microsoft Press, Redmond, Washington, available at: http://www.bisenter.com.

Spradley, J.P. (1980), "Summary for Policymakers", in Intergovernmental Panel on Climate Change (Ed.), Climate Change 2013 - The Physical Science Basis, Cambridge University Press, Cambridge, pp. 1-30.

Stern, H. and Becker, T. (2017), "Development of a Model for the Integration of Human Factors in Cyberphysical Production Systems", 7th Conference on Learning Factories, CLF 2017 Development, The Author(s), Vol. 9, pp. 151-158.

Wang, L., Törngren, M. and Onori, M. (2015), "Current status and advancement of cyber-physical systems in manufacturing”, Journal of Manufacturing Systems, The Society of Manufacturing Engineers, Vol. 37 , pp. 517-527.

Womack, J.P. and Jones, D.T. (2003), “Lean Thinking : Banish Waste and Create Wealth in Your Corporation”, Free Press.

Yin, R.K. (2009), Case Study Research: Design and Methods, 4th Edition, Vol. 5, SAGE Publications, Inc, Thousand Oaks, California 91320.

Zahra, S.A. and Newey, L.R. (2009), "Maximizing the impact of organization science: Theory-building at the intersection of disciplines and/or fields", Journal of Management Studies, Vol. 46 No. 6, pp. 1059-1075.

Zezulka, F., Marcon, P., Vesely, I. and Sajdl, O. (2016), "Industry 4.0 - An Introduction in the phenomenon", IFAC-PapersOnLine, Elsevier B.V., Vol. 49 No. 25, pp. 8-12. 